Madrygal. Revista de Estudios Gallegos

ISSN: 1138-9664

\title{
A proxección da cultura galega desde o Centro de Estudos Galegos da UCM (2017-2018)
}

Paula Cousillas Pena ${ }^{1}$

Así como se levou a cabo en anos anteriores, a proxección da lingua e da cultura galegas continuou desde o Centro de Estudos Galegos da Universidade Complutense de Madrid a súa andaina neste curso 2017-2018.

Cabe destacarmos en primeiro lugar a celebración do Día das Letras Galegas o 21 de maio na Biblioteca Histórica Marqués de Valdecilla, coa participación da profesora e investigadora Montse Pena, como biógrafa da homenaxeada María Victoria Moreno, e David Castro, como director do centro IES Torrente Ballester de Pontevedra, no que se levou a cabo unha enorme difusión desta figura e, precisamente, onde María Victoria exerceu como profesora nos seus últimos anos de vida. Ademais, nese mesmo día tivo lugar a presentación do volume 20 regular da revista Madrygal, na que participaron a directora Carmen Mejía, o co-secretario Ricardo Pichel e o profesor Juan M. Ribera Llopis.

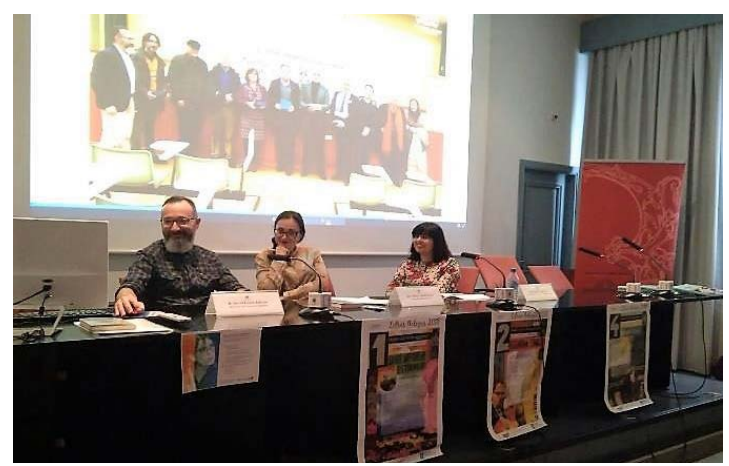

Conferencia de David Castro.

Á dereita, Paula Cousillas e Monte Pena Presas
Como novidade, neste mesmo ano 2017, o equipo de Madrygal preparou un número especial (núm. 20), titulado Os estudos galegos en tempos de cambio e transformación: de Bos Aires a Galicia, no que se recolle unha escolma de colaboracións, que formaron parte do XI Congreso da Asociación Internacional de Estudos Galegos (AIEG), celebrado en abril de 2015 en Bos Aires. Nese encontro, a directora da revista Madrygal, Carmen Mejía, foi elixida presidenta da AIEG para o trienio 2015-2018 e comprometeuse a elaborar o antedito número especial que agora saíu a luz, e que foi presentado no marco do XII Congreso da AIEG celebrado en Madrid.

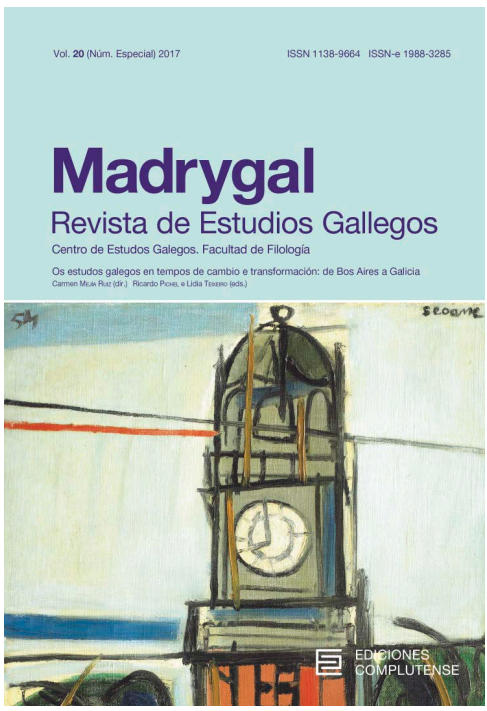

Madrygal. Revista de Estudios Gallegos Núm. 20 Especial (2017)

Universidad Complutense de Madrid, Departamento de Estudios Románicos, Franceses, Italianos y Traducción.

Correo-e: paulacou@ucm.es 
Así mesmo, desde o Centro de Estudos Galegos de Madrid proxectamos a importancia do mundo medieval para a cultura e a literatura galegas coa participación do investigador e antigo lector Ricardo Pichel, quen asistiu as aulas de Galego I o 24 de xaneiro para falar da importancia do mecenado cortesán e señorial do noso patrimonio textual antigo. Así mesmo, tamén aproveitamos para incidir na relevancia do Pergamiño Vindel na configuración da nosa historia lingüística e literaria, participando co noso alumnado e varios representantes dos CEG de fóra de España nunha visita guiada, organizada pola Secretaria Xeral de Política Lingüística, á exposición "Pegamiño Vindel. Un tesouro en sete cantigas" do Museo do Mar en Vigo, na que puidemos admirar, entre outros, o manuscrito coas cantigas de Martín Codax, custodiado na Morgan Library de Nova York. Cabe destacarmos desta visita a presentación do propio pergamiño a cargo de Ricardo Pichel e a visita á Illa de San Simón.

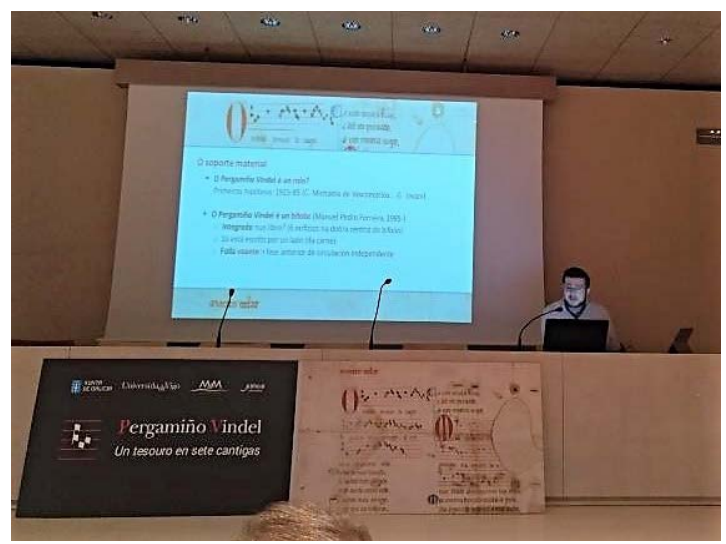

Conferencia de Ricardo Pichel no Museo do Mar de Vigo sobre o Pergamiño Vindel

A importancia da poesía na realidade cultural galega e a súa explotación como potencial didáctico foi outro dos temas que intentamos trasladar ao alumnado de galego. Desta maneira, en marzo de 2018 asistiu ás aulas de galego a anterior lectora Lidia López Teixeiro, para presentar o libro colectivo Poliedro da soidade, como proxecto didáctico xestado co seu alumnado nas aulas.

O maior contributo que realizou o alumnado desde as aulas de galego, por exerceren como axentes activos na visibilización da lingua galega en Madrid, en concreto dentro da Facultade de filoloxía da Complutense, foi a actividade $U n$ ollar por Madrid, a que lle dedicamos unha explicación máis demorada noutro dos capítulos da sección Crónica deste número de Madrygal.
Ademais do anterior, e como vén sendo costume, participamos no roteiro rosaliano que cada ano ten lugar en Madrid no mes de febreiro, para homenaxear o nacemento dunha das autoras máis relevantes da nosa cultura. $\mathrm{O}$ director e secretario de Olga. Revista de poesía galega en Madrid, Vicente Araguas e Manuel Pereira Valcárcel, promoven e organizan este acto, no que este ano participou tamén unha banda de gaita, que amenizou o acostumado roteiro desde a Praza de San Ildefonso ata a casa de Rosalía (Rúa da Ballesta, 13), onde se recitaron diferentes poemas da autora.

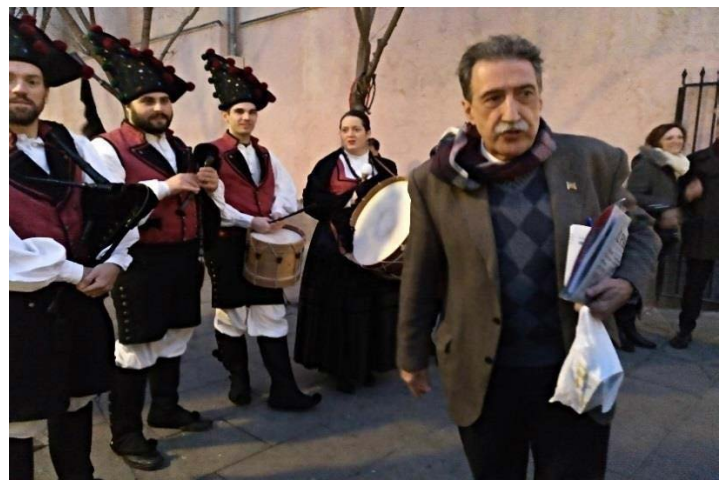

O escritor Vicente Araguas co grupo de gaitas no roteiro rosaliano

En relación coa mencionada revista Olga, o CEG tamén participou na presentación do núm. 4 (decembro 2017), dedicado a Portugal, na Biblioteca Marqués de Valdecilla. O director da revista, Vicente Araguas, fixo especial fincapé na importancia da relación históricocultural entre Galicia e Portugal, mentres que eu mesma, a profesora de portugués Maria Colom e algúns alumnos seus recitamos algúns versos en lingua portuguesa para completar este acto. Meses máis tarde, asistimos tamén á presentación do núm. 5 de Olga (maio 2018), dedicado á figura de Ricardo Carvalho Calero.
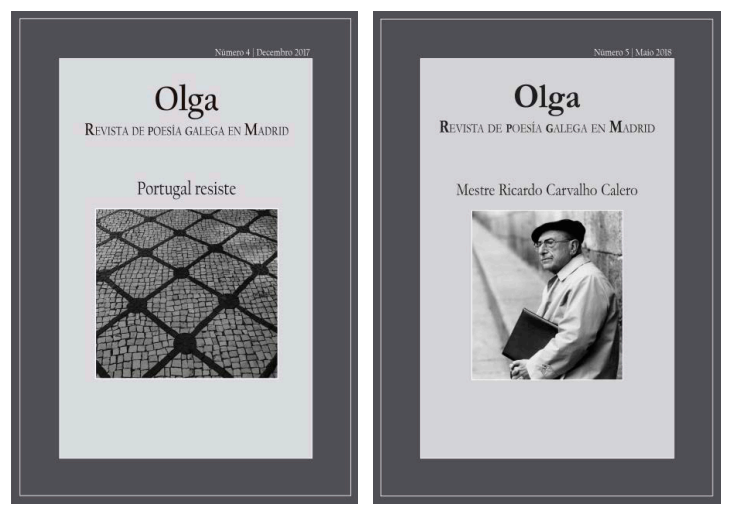

Núms. 4 e 5 da revista poética $\operatorname{Olg} a$ 
Destacamos tamén a celebración da diversidade lingüística que a Facultade de filoloxía da UCM levou a cabo como motivo principal de "La fiesta de las lenguas y de las letras" na semana do 15 de maio. Un evento no que o galego e, por tanto, o CEG, puido participar dentro dunha das súas actividades. En concreto, puidemos deixar a nosa impronta na alfombra de papel xigante que foi colocada no exterior das inmediacións, escribindo algúns versos emblemáticos en galego da nosa literatura, tales como a longa noite de pedra de Celso Emilio, o afogado berro de vida dos versos de Lois Pereiro ou a reivindicación feminista de Ana Romaní.

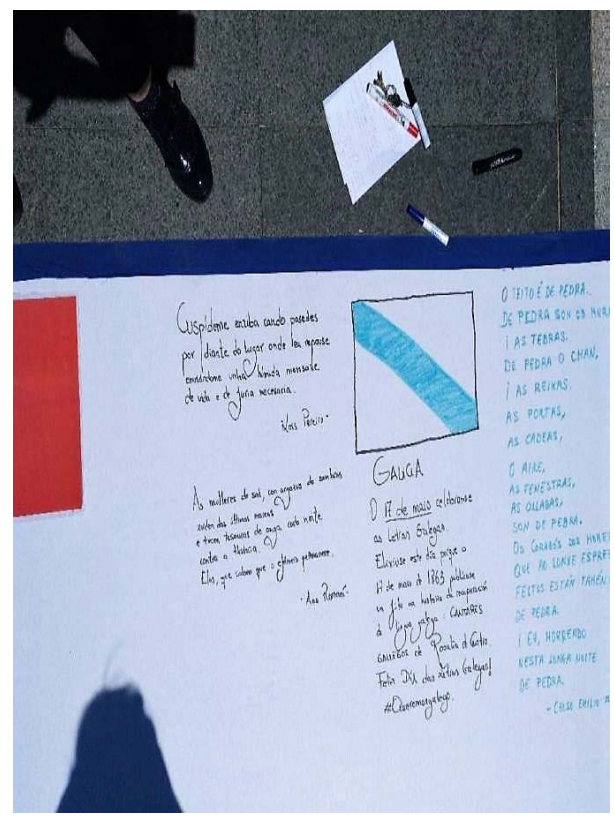

Unha mostra da alfombra das linguas, onde está o espazo do galego

Por outro lado, o compromiso do CEG coa docencia e a difusión da lingua galega en Madrid reflectímolo na difusión do acto "Contra vento e maré", no que se presentaron as antoloxías literarias creadas nas aulas de galego e de portugués polas profesoras Lidia Teixeiro, co volume en papel $O$ poliedro da soidade, e Maria Colom, co volume en versión dixital Somos a resistência: contra a tempestade. Nesta presentación, celebrada o 23 de abril na libraría Meta Librería, as ditas profesoras e o alumnado asistente explicaron de maneira moi emotiva como xurdiu a idea, como levaron a cabo o proxecto e que supuxo para eles na súa aprendizaxe.

No Día da Poesía, o 20 de marzo, as profesoras de portugués e de galego quixemos difundir a nosa lingua celebrando este día na Facultade de filoloxía cun recital que denominamos

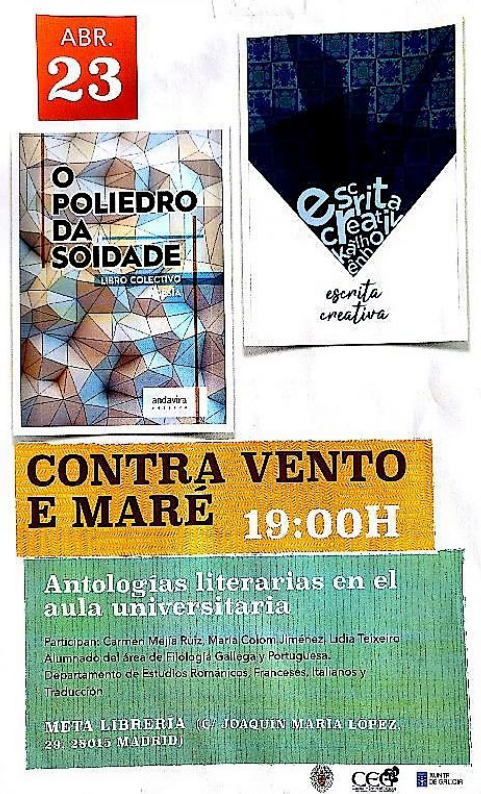

Cartel do acto "Contra vento e maré"

Poetas da liberdade. Os poemas foron lidos polo alumnado no Salón de Actos do Edificio A desta facultade, creándose un ambiente de recoñecemento mutuo entre ambas as dúas linguas irmás.

Finalmente, e para dar cabo a esta breve crónica, non podemos esquecer a suma relevancia que tivo o CEG de Madrid na proxección internacional da lingua galega, xa que a súa directora, Carmen Mejía, en calidade de presidenta da Asociación Internacional de Estudos Galegos, organizou xunto co seu equipo o XII Congreso Internacional da AIEG, titulado Novos horizontes para unha Galicia Global: redes, territorio e memoria, e baixo o lema "Madrid, cidade de encontros", e que se celebrou do 10 ao 15 de setembro de 2018 na Facultade de filoloxía da UCM

Neste congreso, caracterizado pola súa interdisciplinariedade e o intenso intercambio cien-tífico, participaron máis de douscentos galicianistas chegados de todas as partes do mundo (https://www.aieg18.com). Debemos salientar aquí a nosa enorme satisfacción para co labor desenvolto e para coa boa disposición de todos os congresitas e todos os organismos madrileños, que facilitaron a celebración de diferentes actos do congreso, tales como a súa apertura, na Casa de Galicia, ou a súa clausura, no Ateneo de Madrid, ou incluso a colaboración da Real Biblioteca de San Lorenzo do Escorial e do seu director D. José Luis del Valle Merino, onde fixemos unha visita guiada para 


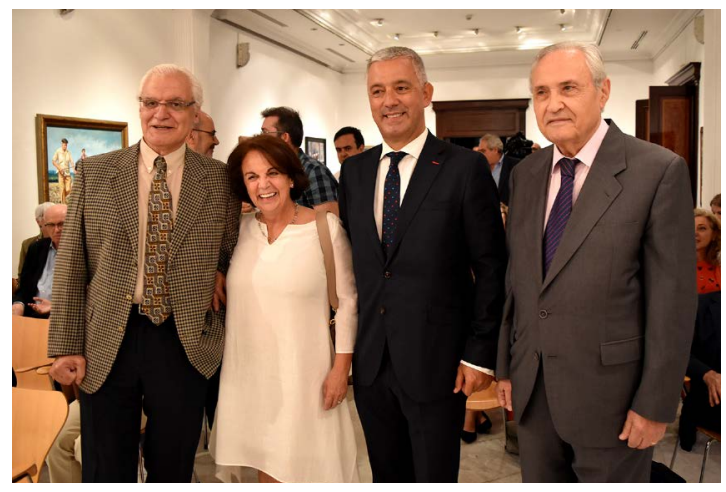

Inauguración do congreso na Casa de Galicia. Víctor Freixanes, Carmen Mejía, Valentín García e José Ramón Ónega

vermos os códices das Cantigas de Santa María (Códice Rico e Códice dos Músicos) e gozarmos dun concerto a cargo de Carlos Núñez e os seus músicos (Pancho Álvarez e Xurxo Núñez), os rapaces da Escolanía do Escorial e o Profesor Harvey L. Sharrer (Universidade de California, Santa Bárbara), quen recitou o prólogo das Cantigas do rei Sabio.

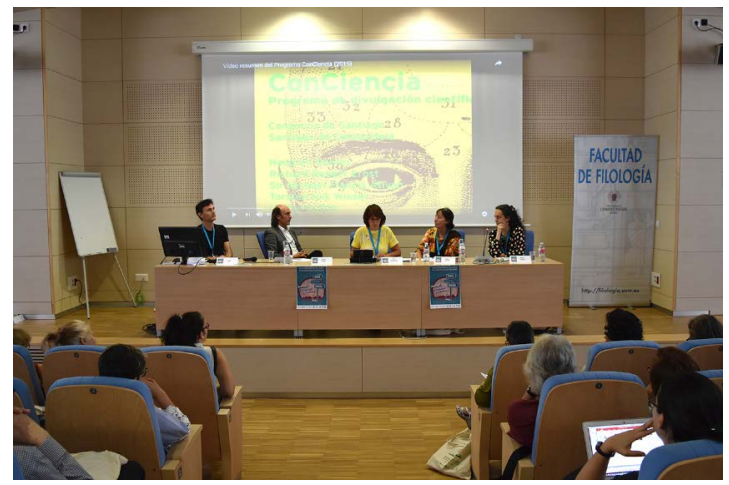

Mesa redonda sobre Redes no congreso. Jorge Mira, Carlos Núñez, Olivia Rodríguez, Mabel Rivera e Débora Campos

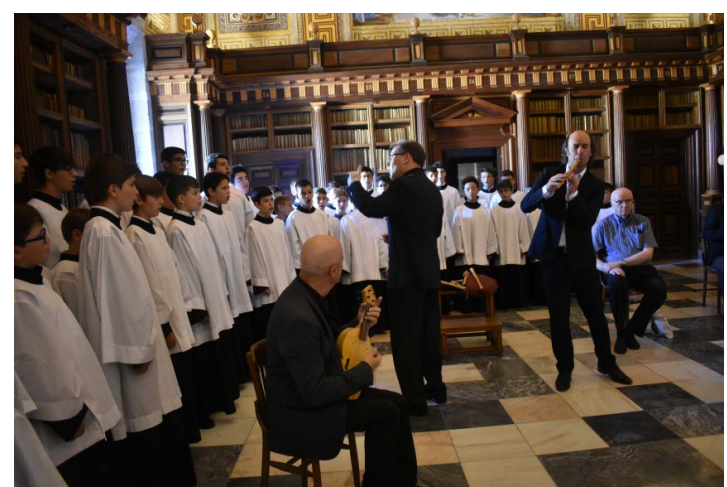

Concerto de Carlos Núñez, os seus músicos e a Escolanía do Escorial

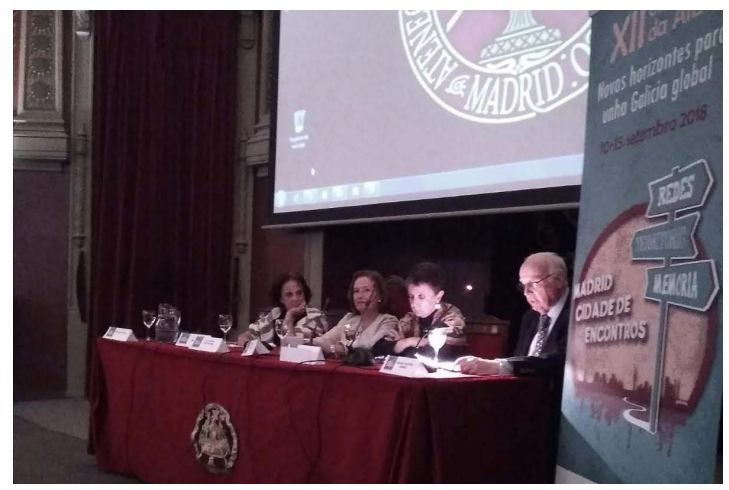

Clausura do congreso no Ateneo de Madrid. Carmen Mejía, María Lourdes Batán Aira, Kathleen N. March e Harvey L. Sharrer

Tamén foi importante neste congreso a celebración da asamblea extraordinaria dos membros da asociación, na que se elixiu o novo equipo directivo. Desta maneira, a profesora Maria Boguszewicz, da Universidade de Varsovia, erixiuse como a nova presidenta da AIEG, quen deberá levar a cabo o enorme labor de organizar o próximo congreso internacional en 2021.

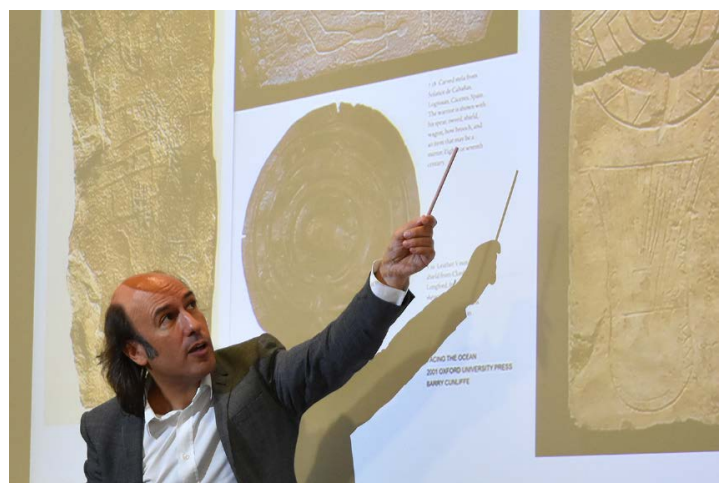

Conferencia plenaria de Carlos Núñez no XII Congreso da AIEG

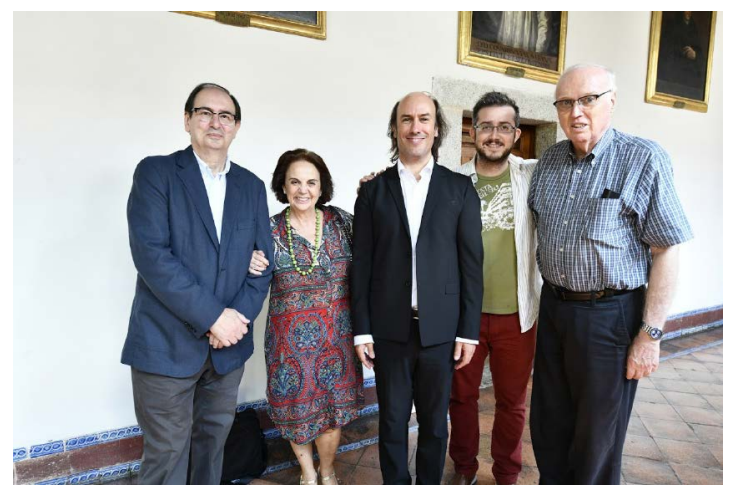

José Luis del Valle, Carmen Mejía, Carlos Núñez, Ricardo Pichel e Harvey L. Sharrer no Escorial 